\title{
Operational Status of Urban Gardens to Derive Necessary Items of Public Urban Garden Management Guidelines
}

\author{
In-Kyoung Hong ${ }^{1}$, Hyung-Kwon Yun ${ }^{2 *}$, Young-Bin Jung ${ }^{3}$, and Sang-Mi Lee ${ }^{3}$ \\ ${ }^{1}$ Post-doctoral associate, National Institute of Horticultural and Herbal Science, Wanju-gun 55365, Korea \\ ${ }^{2}$ Senior researcher, National Institute of Horticultural and Herbal Science, Wanju-gun 55365, Korea \\ ${ }^{3}$ Researcher, National Institute of Horticultural and Herbal Science, Wanju-gun 55365, Korea
}

\section{ABSTRACT}

The purpose of this study was to understand the current status of education and programs and to identify the items that urban residents need most for garden management. First of all, there were 45 sites (40.5\%) with gardens operated by city and county local governments nationwide, and $41(91.1 \%)$ of them had dedicated staff (1.8 persons on average). The average area of gardens was $18,623 \mathrm{~m}^{2}$, garden area per person was $20.27 \mathrm{~m}^{2}$, the average number of participants was 683 , and the average period of use was 8.69 months. In addition to gardening activities, 14 (31.1\%) out of 45 sites were operating small group meetings, with an average of 2.29 meetings and 67 participants. In the satisfaction survey after gardening activities, $88.9 \%$ of 18 sites were satisfied. According to the questionnaire about education and programs related to garden users, an average of four sessions were conducted per education. In terms of education, the contents were in the following order: basic education on garden cultivation (33.9\%) $>$ prior education on garden operation (28.9\%) $>$ pest control (14.0\%) > eco-friendly management (11.6\%) > pesticides and Positive List System (9.9\%) $>$ others (1.7\%). Over $95 \%$ of the respondents were generally satisfied. Regarding the perception survey on which items are needed to develop garden management guidelines, the most necessary items were in the order of crop management (38.7\%) $>$ public garden etiquettes among users (27.9\%) $\rangle$ pest control (14.4\%) $\rangle$ weed management (13.5\%) $\rangle$ activities using harvest (5.4\%). The contents that are to be included in the guidelines were in the order of garden planning and crop selection (17.2\%) $>$ cultivation techniques and schedule (16.5\%) $>$ pest and soil management (15.7\%) $>$ introduction of garden crops and gardening models $(12.7 \%)>$ garden etiquettes (10.7\%). In establishing urban garden management plans by region, the results will have high utility value as the basic data for continuous garden operation by setting a direction that meets the regional characteristics as well as the needs of urban residents.

Keywords: education program, healing, perception, space, urban agriculture

\section{Introduction}

As the standards of living improved worldwide and urban residents enjoying leisure and relaxing in nature begin to have more and more needs, urban gardens are rapidly expanding as a community space for sound leisure activities for urban residents exhausted by the city life (Lee, 2013). Urban agriculture is also spreading in South Korea, with local governments and civic groups supplying urban gardens (Lee, 2017), and various activities of urban agriculture are proving value in many fields such as health, society, economy and ecology, giving rise to public interest in urban agriculture (Hong et al., 2019). The government is making more efforts to activate urban agriculture, and administrative districts under jurisdiction and local governments are carrying out various types of gardening projects to promote urban agriculture (Cho, 2015). Participants and garden areas increased remarkably with the urban agri-

This paper is funded by Rural Development Administration's specialized project (PJ01438501).

Received: February 20, 2020, Revised: March 9, 2020, Accepted: March 20, 2020

First author: In Kyoung Hong, inkyoung63@korea.kr, (1) https://orcid.org/0000-0002-7050-5413

*Corresponding author: Hyung Kwon Yun, yun0309@korea.kr, (10) https://orcid.org/0000-0001-9973-4706 
culture development policy by the government and local governments, and urban agriculture is continuously expanding with the vitalization policy of the Ministry of Agriculture, Food, and Rural Affairs and local governments, as well as technology development and supply of Rural Development Administration, and activities of private organizations (Youn, 2018). The policy goal of the Ministry of Agriculture, Food and Rural Affairs to vitalize urban agriculture is also to secure 3,000ha of urban green space and 8,000 urban gardens by 2020 (Ministry of Agriculture, Food and Rural Affairs, 2011). This reflects the trend in which the number of users willing to participate in urban agriculture is gradually increasing as the scope of urban agriculture is expanding from metropolitan areas to nationwide. According to the data of Statistics Korea, the farming population in all rural areas is decreasing every year, whereas the population participating in urban agriculture is rapidly increasing, which represents that citizens' interest in urban agriculture is constantly growing (Kim, 2018). With the increasing citizen use of urban agriculture, the government has adopted the Urban Agriculture Manager system as a national professional license for interpretation, education, guidance and technology transfer related to urban agriculture to promote understanding among urban residents. Through Urban Agriculture Managers, the government is also relaxing regulations and establishing the foundation to vitalize urban agriculture to let the urban residents know about the multiple values of urban agriculture and the new value of agriculture and rural areas (Ministry of Agriculture, Food, and Rural Affairs, 2017). It is necessary to provide ways to constantly vitalize urban agriculture and maintain continuous participation in urban agriculture, and there must also be government-led support policies as well as actual field-based solutions considering the participants (Choi, 2016).

Since the 1990s when the discussions about urban agriculture first began, there has been emphasis on the national interest in the public value of agriculture, urban-rural exchange, and agriculture/rural areas (Jang et al., 2012). Interest and demand for urban agriculture are also growing among the media, citizens and organizations since the topic was made publicized in 2010 (Lee, 2013). Previous studies on urban agriculture in Korea published since 2000 are ones on vitalization of urban agriculture, policy assessment and valuation of urban agriculture, management type of urban agriculture, activities of urban agriculture, and types of urban agriculture as well as programs. Most of them came up with institutional support plans by analyzing cases in Korea and overseas, and suggested vitalization of urban agriculture. Studies on the management state of public gardens were limited to only a few big cities, whereas there was insufficient research on how urban gardens must be actually managed (Park, 2012), without specific discussions on management guidelines. Kim et al. (2015) suggest that gardens formed under the management of local governments have benefits in terms of support, but lack environment or continuous management. Kim (2018) stated that urban residents still showed low satisfaction despite the government policy and support. Thus, considering that the government's urban agriculture policy is for urban residents, it is necessary to determine the demand for items that are most necessary for garden management along with satisfaction of urban residents as the actual users in order to establish an effective urban agriculture policy. Therefore, this study was conducted to determine the current state of public urban gardens in local governments that are run as part of the urban agriculture vitalization plan as well as the management status of training programs for gardening activities, and to provide data for vitalization of urban agriculture. Furthermore, this study will determine the urban agriculture satisfaction of citizens participating in gardening activities through the public servants in charge of urban agriculture, as well as necessary items for continuous urban gardening activities. This can be used as the basic data required in establishing the foundation for urban agriculture to meet the needs and demands of urban residents when seeking Korean-style urban agriculture garden management plans or developing management guidelines.

\section{Research Methods}

This study is conducted to derive necessary items in seeking plans for continuous use of urban gardens. To determine the actual state of garden management, we conducted a survey for 47 days from March 29 to May 14, 2019 with urban agriculture personnel in provincial in- 
stitutes and city and county agricultural technology centers in Korea (162 institutes and centers). There were total 30 survey items: four items on demographic characteristics, six items on the current state of urban gardens derived from related literature review (Cho, 2015; Jang et al., 2012; Kim, 2018; Lee, 2013), eight items on group meetings of gardening activity participants, eight items on gardening education and programs, and four items on necessary items to seek garden management plans (Table 1). To conduct this study, we requested and collected data on management of relevant departments of urban agriculture nationwide in January 2019. Based on this data and previous studies, we redeveloped the questionnaire in the order of garden management status including small group meetings, education and programs, and guidelines for garden management. The purpose and content of the survey were sufficiently explained to the respondents, after which they responded to the survey in a self-report method. The survey on garden status and education was conducted according to the actual cases of management, and to survey many samples, all respondents were to respond to the items for management guidelines regardless of whether they participated in garden management or education.

Total 162 copies of the questionnaire were distributed via email, visit and mail, 111 of which were collected and summed up on Excel, and then analyzed using IBM SPSS statistics Ver. 25. A frequency analysis and descriptive analysis were conducted on the demographic characteristics of participants, garden management and education, and satisfaction after the activities. A reliability analysis was conducted to verify the internal consistency of education and program components, thereby calculating Cronbach's alpha. An independent samples t-test was conducted at the significance level of $95 \%$ to verify the perception gap of satisfaction by gender. We also conducted a correlation analysis to determine the relationship among key items of garden management, and a chi-square test to compare the perception gap in key items by demographic characteristics.

\section{Results and Discussion}

\section{Demographic characteristics of respondents}

The demographic characteristics of respondents are as shown in Table 2. There were 64 male (57.7\%) and 47 female $(42.3 \%)$ respondents, and none of them were under 20,38 were in their $40 \mathrm{~s}(34.2 \%)$, followed by 32 in their $30 \mathrm{~s}(28.8 \%), 30$ in their $20 \mathrm{~s}(27.0 \%)$, and 11 in their $50 \mathrm{~s}$ $(10.0 \%)$. Most of them were university graduates $(82.0 \%)$, followed by graduate school (17.1\%) and high school $(0.9 \%)$, and no two-year college graduates. By region, all copies of the questionnaire were retrieved from Seoul (1), Jeju (1), metropolitan cities (7), and Chungcheongnam-do (15), 90\% from Chungcheongbuk-do (11) and Gyeongsangnam-do (17), and 78.6\% from Jeollabuk-do (14). The highest response was in Gangwon-do $(12,66.7 \%)$, followed by Gyeonggi-do (17, 54.8\%), Jeollanam-do (10, 45.4\%) and Gyeongsangbuk-do (9, 43.5\%).

Table 1. Contents of survey

\begin{tabular}{|c|c|c|c|c|}
\hline $\begin{array}{l}\text { Survey } \\
\text { No. }\end{array}$ & Item & Contents & $\begin{array}{l}\text { No. of } \\
\text { Item }\end{array}$ & Reference \\
\hline DV1-DV4 & Demographic characteristics & Gender, age, residence, education level & 4 & - \\
\hline V1-V14 & $\begin{array}{l}\text { Operation of garden and small } \\
\text { groups meeting }\end{array}$ & $\begin{array}{l}\text { Urban garden operation, dedicated staff \& average number of staff, total } \\
\text { garden area, garden area per person, number of participants, period of } \\
\text { use, number of small group meeting, participants per group, satisfaction } \\
\text { research \& result }\end{array}$ & 14 & $\begin{array}{l}\text { Lee(2013), } \\
\operatorname{Kim}(2018)\end{array}$ \\
\hline V15-V22 & Rural education and program & $\begin{array}{l}\text { Number of times per training, total educational expenses, instructor fee, } \\
\text { material cost, education contents, satisfaction research \& result }\end{array}$ & 8 & $\begin{array}{l}\text { Jang et al. } \\
\text { (2012) }\end{array}$ \\
\hline V23-26 & $\begin{array}{l}\text { Guidelines of urban garden for } \\
\text { the management }\end{array}$ & $\begin{array}{l}\text { Rankings of the garden management, emphasis contents, suggestion of } \\
\text { guidelines, content ranking that you want to include in the guidelines }\end{array}$ & 4 & $\begin{array}{l}\operatorname{Cho}(2015) \\
\operatorname{Kim}(2018)\end{array}$ \\
\hline
\end{tabular}


Table 2. The respondent's demographic characteristics

\begin{tabular}{|c|c|}
\hline Item & $\mathrm{n}(\%)$ \\
\hline \multicolumn{2}{|l|}{ Gender } \\
\hline Male & $64(57.7)$ \\
\hline Female & $47 \quad(42.3)$ \\
\hline Total & $111(100.0)$ \\
\hline \multicolumn{2}{|l|}{ Age } \\
\hline $20 \mathrm{~s}$ & $30(27.0)$ \\
\hline $30 \mathrm{~s}$ & $32(28.8)$ \\
\hline $40 \mathrm{~s}$ & 38 (34.2) \\
\hline $50 \mathrm{~s}$ & $11(10.0)$ \\
\hline Total & $111(100.0)$ \\
\hline \multicolumn{2}{|l|}{ Education level } \\
\hline High school & $1(0.9)$ \\
\hline University & $91(82.0)$ \\
\hline Graduate school & $19(17.1)$ \\
\hline Total & $111(100.0)$ \\
\hline \multicolumn{2}{|l|}{ Residence } \\
\hline Seoul $(1)^{z}$ & $1(0.9)$ \\
\hline Metropolitan city (7) & $7(6.3)$ \\
\hline Gyeonggi-do (31) & $17(15.3)$ \\
\hline Gangwon-do (18) & $12(10.8)$ \\
\hline Chungcheongbuk-do (12) & $11(9.9)$ \\
\hline Chungcheongnam-do (15) & $15(13.5)$ \\
\hline Jeollabuk-do (14) & $11(9.9)$ \\
\hline Jeollanam-do (22) & $10(9.0)$ \\
\hline Gyeongsangbuk-do (23) & $9(8.1)$ \\
\hline Gyeongsangnam-do (18) & $17(15.3)$ \\
\hline Jeju-do (1) & $1(0.9)$ \\
\hline Total & $111 \quad(100.0)$ \\
\hline
\end{tabular}

${ }^{\mathrm{z}}$ Numbers in the parentheses respresent the number of sites in the region.

\section{Current state of public garden operation and satisfaction survey after gardening activities}

\section{Current state of public garden operation}

This study is a survey to determine the status of public garden operation and group meetings, which selected and analyzed the components of previous studies. From 111 copies of the retrieved questionnaire, the results showed that 45 sites $(40.5 \%)$ had gardens operated by city and county local governments since less than 5 years ago until the present, and 66 sites (59.5\%) did not. Out of 45 sites, $41(91.1 \%)$ had dedicated staff (Table 3).
Table 3. Basic operation status of public urban gardens

\begin{tabular}{lcc}
\hline \multicolumn{1}{c}{ Item } & $\mathrm{n}(\%)$ \\
\hline Local government operates urban gardens & & \\
$\quad$ Yes & 45 & $(40.5)$ \\
No & $66(59.5)$ \\
$\quad$ Total & $111(100.0)$ \\
Dedicated staff in public urban gardens & \\
Yes & $41(91.1)$ \\
No & $4(8.9)$ \\
Total & $45(100.0)$ \\
\hline
\end{tabular}

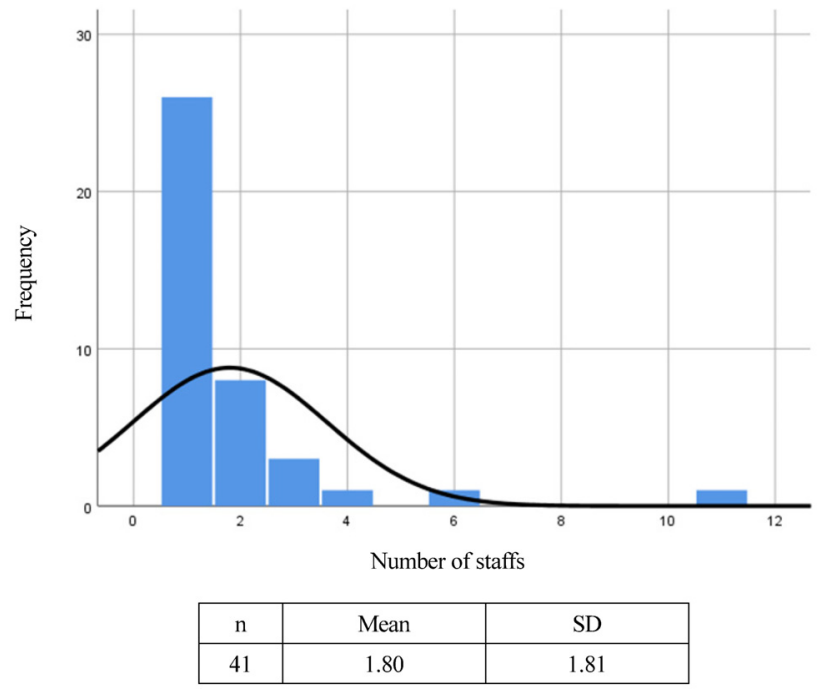

Fig. 1. Average number of staffs working in public urban gardens.

To check the visual distribution using a histogram (Fig. 1 ), the $\mathrm{x}$-axis showed the number of staff and the $\mathrm{y}$-axis showed the frequency. As a result. 1-2 persons turned out to be the highest, and an average of 1.8 persons were spending 4 weeks a week in managing and operating the garden.

The mean of total garden area was $18,623.09 \mathrm{~m}^{2}$ (minimum $300 \mathrm{~m}^{2}$, maximum $123,770 \mathrm{~m}^{2}$ ) and the garden area per person was $20.27 \mathrm{~m}^{2}$. The average number of participants was 683 (minimum 10 persons, maximum 7,500 persons), and the average period of garden use was 8.69 months (minimum 2 months, maximum 12 months). This was consistent with the study by Kim (2018) in which the area that is easy to manage when the government or an institution parcels out its gardens is $15-20 \mathrm{~m}^{2}$. By region, the size is bigger in small and mid-sized cities, and smaller 
Table 4. Size of the public urban garden area and participants

\begin{tabular}{lccc}
\hline \multicolumn{1}{c}{ Item } & $\mathrm{n}$ & Mean & SD \\
\hline Total garden area $\left(\mathrm{m}^{2}\right)$ & 44 & $18,623.09$ & $30,561.52$ \\
Garden area per person $\left(\mathrm{m}^{2}\right)$ & 43 & 20.27 & 21.30 \\
Number of participants (person) & 43 & 682.72 & $1,299.31$ \\
Period of garden use (month) & 45 & 8.69 & 1.95 \\
\hline
\end{tabular}

Table 5. Small group meetings among public urban garden participants

\begin{tabular}{lccc}
\hline \multicolumn{1}{c}{ Item } & $\mathrm{n}$ & Mean & SD \\
\hline Number of small group meetings & 14 & 2.29 & 1.49 \\
Number of participants per group & 14 & 66.85 & 132.54 \\
\hline
\end{tabular}

Table 6. Satisfaction of participants after gardening activities in public urban gardens

\begin{tabular}{|c|c|c|c|}
\hline Item & $\mathrm{n}(\%)$ & Item & $\mathrm{n}(\%)$ \\
\hline Small group participation & & Satisfaction degree & \\
\hline Yes & $14(31.1)$ & Very unsatisfied & $2(11.1)$ \\
\hline No & $31(68.9)$ & Neutral & $1(5.6)$ \\
\hline Total & $45(100.0)$ & Satisfied & $8(44.4)$ \\
\hline Response to satisfaction questions & & Very satisfied & $7(38.9)$ \\
\hline Yes & $18(40.0)$ & Total & $18(100.0)$ \\
\hline No & $27(60.0)$ & & \\
\hline Total & $45(100.0)$ & & \\
\hline
\end{tabular}

in big metropolitan cities, which implies that there is difficulty in securing the land to parcel out or rent gardens as well as the burden of cost. The area of urban gardens currently operated, the number of participants, and period of use are as shown in Table 4.

Out of 45 sites operated by local governments, 14 sites (31.1\%) were operating group meetings of participants who rent the plots in the gardens. There were an average of 2.29 small group meetings in operation, and 67 participants in each group (Tables 5 and 6).

\section{Satisfaction survey for gardening activities and perception gap in satisfaction by gender}

Regarding whether a satisfaction survey is conducted after gardening activities, $40 \%$ responded 'yes' and $60 \%$ 'no'. For 18 sites that had satisfaction surveys, $83.9 \%$ responded 'satisfied', 5.6\% responded 'neutral', and 11.1\% responded 'not satisfied' indicating that the respondents were satisfied in general. The reasons for the high sat- isfaction were harvest of fresh crops, harmony among family members, healthy leisure, interaction with others, communication among residents, improvement of dietary life, cultivation of an upright character, and maintenance of the community (Table 6).

As for the perception gap in satisfaction of gardening activities by gender, male respondents showed a higher score with 4.11 ( $\mathrm{SD}=1.269)$, but there was no statistically significant difference (Table 7).

\section{Implementation of education and programs and contents of education}

\section{Intemal consistency analysis by factor of education and program components}

As a result of the reliability analysis to verify the internal consistency by factor by selecting the components of education and programs, Cronbach's $a$, which represents internal consistency among all factors, was .718 as shown 
Table 7. Satisfaction after garden activities by gender

\begin{tabular}{cccccc}
\hline Gender & $\mathrm{n}(\%)$ & Mean(SD) & $\mathrm{t}$ & $\mathrm{df}$ & $p$ \\
\hline Male & $9(50.0)$ & $4.11(1.269)$ & 0.371 & 16.000 & $.715^{\text {NS }}$ \\
Female & $9(50.0)$ & $3.89(1.269)$ & & \\
\hline
\end{tabular}

${ }^{\mathrm{NS}}$ Non-significant by t-test.

Table 8. Reliability analysis of education and program components

\begin{tabular}{lccc}
\hline \multicolumn{1}{c}{ Item } & $\begin{array}{c}\text { Corrected Item-Total } \\
\text { Correlation }\end{array}$ & $\begin{array}{c}\text { Cronbach's } a \\
\text { If Item Deleted }\end{array}$ & Cronbach's $a$ \\
\hline Training of garden users & .000 & .736 \\
Number of times per education & -.543 & .736 \\
Total education expenses & .997 & .550 \\
Instructor fee & .986 & .570 \\
Material cost & .995 & .466 \\
Participant satisfaction survey & .000 & .736 \\
Satisfaction result & -.198 & .736 \\
\hline
\end{tabular}

Table 9. Educations or programs for public urban garden users

\begin{tabular}{|c|c|c|c|}
\hline Item & $\mathrm{n}(\%)$ & Item & $\mathrm{n}(\%)$ \\
\hline Education or program for users & & Satisfaction degree & \\
\hline Yes & $45(40.5)$ & Very unsatisfied & $1(4.8)$ \\
\hline No & $66(59.5)$ & Satisfied & $13(61.9)$ \\
\hline Total & $111(100.0)$ & Very satisfied & $7(33.3)$ \\
\hline Satisfaction survey after education & & Total & $21(100.0)$ \\
\hline Yes & $21(46.7)$ & & \\
\hline No & $24(53.3)$ & & \\
\hline Total & $45(100.0)$ & & \\
\hline
\end{tabular}

in Table 8, showing a high level of internal consistency.

\section{Implementation of education and programs}

Among 111 copies of the retrieved questionnaire, 45 sites $(40.5 \%)$ responded that they have implemented or are implementing education or programs for urban garden users. However, there may be a gap in the results as the data of certain areas that no longer operate the programs due to lack of funding among the 45 sites. Satisfaction surveys after gardening education were conducted by 21 (46.7\%) out of 45 sites, and most of the participants (95.2\%) seemed to be satisfied (Table 9). This is consistent with the report by Hong et al. (2018), indicating that interest in gardens is constantly growing according to sat- isfaction in gardening activities.

The average number of sessions per program in the 36 sites was four sessions (minimum one session, maximum 24 sessions), and except metropolitan areas and Jeju, other regions were conducting few sessions of education or programs. This is due to the difficulty in securing land for gardening activities, and thus active administrative measures by national institutes may increase participation of users. Out of 45 sites, 24 (53.3\%) that were spending on education and programs, and the total expense required in education for a year was KRW 34,077,740, comprised of KRW 10,313,950 for instructor fees and KRW $13,849,562$ for material costs as well as other costs such as fixed costs for tools and facilities, consumables and labor 
Table 10. Expenses on education and programs for public urban garden users

\begin{tabular}{lccc}
\hline \multicolumn{1}{c}{ Item } & $\mathrm{n}$ & Mean & SD \\
\hline Number of times per training & 36 & 4.44 & 5.05 \\
Total educational expenses (KRW) & 24 & $34,077,740$ & $75,641,680$ \\
Instructor fee (KRW) & 24 & $10,313,950$ & $15,599,332$ \\
Material cost (KRW) & 24 & $13,849,562$ & $25,004,593$ \\
\hline
\end{tabular}

Table 11. Frequency and contents of education for public garden users

\begin{tabular}{lcc}
\hline \multicolumn{1}{c}{ Contents } & Frequency(n) & $\%$ \\
\hline Introduction to garden operation & 35 & 28.9 \\
Basic education on garden cultivation & 41 & 33.9 \\
Pest management & 17 & 14.0 \\
Eco-friendly management & 14 & 11.6 \\
Pesticide and Positive List System & 12 & 9.9 \\
Others & 2 & 1.7 \\
\hline
\end{tabular}

Table 12. Satisfaction about education and programs by gender

\begin{tabular}{cccccc}
\hline Gender & $\mathrm{n}(\%)$ & Mean(SD) & $\mathrm{t}$ & $\mathrm{df}$ & \\
\hline Male & $14(66.7)$ & $4.21(0.426)$ & 0.172 & 19 & $.865^{\mathrm{NS}}$ \\
Female & $7(33.3)$ & $4.14(1.464)$ & & \\
\hline
\end{tabular}

${ }^{\mathrm{NS}}$ Non-significant by t-test.

costs (Table 10).

The expense per person can be calculated by dividing the total cost of KRW 34,077,740 by 683 participants on average and four sessions of education: KRW 12,474 per session.

\section{Contents of education}

The contents of education carried out in 45 sites that provided education and programs for urban garden users were determined by multiple response questions, and as a result of coding by dichotomy, 41 (33.9\%) provided basic education on garden cultivation, followed by 35 (28.9\%) providing prior education on garden operation, 17 (14.0\%) on pest management, $14(11.6 \%)$ on eco-friendly management, $12(9.9 \%)$ on pesticides and Postive List System (PLS), and $2(1.7 \%)$ on other negligent accidents and on-site garden training (1.7\%; Table 11).

\section{Perception gap on education satisfaction by gender}

As for the perception gap in satisfaction of education by gender, male respondents showed higher satisfaction with $4.21(\mathrm{SD}=0.426)$, but there was no statistically significant difference (Table 12).

\section{Survey on key items to establish garden management guidelines}

\section{Survey on items of garden management guidelines}

This study was conducted to come up with items necessary for establishing guidelines related to urban agriculture. All respondents were to respond to the survey regardless of garden management or education in order to survey many samples, and the survey was on what is most important for garden management, whether there are guidelines currently suggested, what contents are provided, and the need for items necessary for future guidelines.

Regarding whether local governments are providing guidelines about management methods for garden participants, 43 sites (38.7\%) responded 'yes', and the content was crop cultivation and management in 37 sites $(46.8 \%)$, followed 
Table 13. Garden management guidelines

\begin{tabular}{|c|c|c|c|}
\hline Item & $\mathrm{n}(\%)$ & Item & $\mathrm{n}(\%)$ \\
\hline Top priority in garden management & & Presence of management guidelines & \\
\hline Pest control & $16(14.4)$ & Yes & $43(38.7)$ \\
\hline Weed management & $15(13.5)$ & No & $68(61.3)$ \\
\hline Crop management & 43 (38.7) & Total & $111(100.0)$ \\
\hline Public garden etiquette & $31(28.0)$ & Contents that should be included in the guidelines & \\
\hline Activities using harvest & $6(5.4)$ & Gardening etiquettes & $59(10.7)$ \\
\hline Total & $111(100.0)$ & Pest and soil management & $87(15.7)$ \\
\hline Contents of current guidelines & & Eco-friendly management technology & $56(10.1)$ \\
\hline Garden planning & $19(24.1)$ & Cultivation technique & $91(16.5)$ \\
\hline Soil management & $9(11.4)$ & Planning garden and selecting crops & $95(17.2)$ \\
\hline Crop introduction & 11 (13.9) & Activity program & $51(9.2)$ \\
\hline Cultivation/Management & 37 (46.8) & Crop disposal & $44(8.0)$ \\
\hline Harvest & $3(3.8)$ & Crop and gardening model introduction & $70(12.7)$ \\
\hline Total & $79(100.0)$ & Total & $553(100.0)$ \\
\hline
\end{tabular}

by garden planning 19 sites (24.1\%), crop introduction 11 sites (13.9\%), soil management nine sites (11.4\%), and use of harvest three sites (3.8\%; Table 13). This was consistent with the study by Kim (2018) that education on crop cultivation techniques is the most necessary institutional support in garden management for urban agriculture.

In the survey about which is most important for garden management, 43 sites (38.7\%) responded it was crop management, followed by public garden etiquettes among users (prevention of disputes) in 31 sites (27.9\%), pest control 16 sites (14.4\%), weed management 15 sites (13.5\%), and activities using harvest (cooking, herbal tea, soap, etc.) six sites (5.4\%; Table 13). This was consistent with the study by Nam (2013) that the emphasis on public garden etiquettes among users is due to the fact that there are conflicts among garden users as there is a contradiction between garden functions and publicness with the increase of gardens.

In the survey on what contents should be included in guidelines for garden management by national institutions, the responses were surveyed in multiple responses and coded by dichotomy. The first in ranking was garden planning and crop selection in 95 sites (17.2\%), followed by cultivation techniques and schedules in 91 sites $(16.5 \%)$, pest and soil management 87 sites (15.7\%), introduction of crops and gardening models 70 sites (12.7\%), and garden etiquettes 59 sites $(10.7 \%$; Table 13$)$. This is similar to the study by Kim (2018), which showed a remarkably high percentage of 'gardening' as intensive training related to urban agriculture that the respondents most want to receive. This result reflects the needs of urban residents trying to make stable management plans before the activities for successful use and management of gardens.

\section{Correlation analysis on important items of garden management}

As a result of obtaining Pearson's r, the correlation coefficient of variables by selecting important items of garden management, there was a correlation between pest control and activities using harvest; crop management, public garden etiquettes among users and activities using harvest; and public garden etiquettes among users and activities using harvest as shown in Table 14, showing statistically significant results. However, Kang (2016) claimed that correlation coefficient of .39 or lower has little relevance, and thus the correlation is low. Pest control and weed management, crop management, public garden etiquettes among users and weed management and crop management, public garden etiquettes among users, activities using harvest, etc. did not show statistically significant results at the significance level of $5 \%$. 
Table 14. Correlation between important items in garden management

\begin{tabular}{|c|c|c|c|c|c|}
\hline Item $^{y}$ & A & B & $\mathrm{C}$ & $\mathrm{D}$ & E \\
\hline A & 1 & & & & \\
\hline B & -.132 & 1 & & & \\
\hline $\mathrm{C}$ & -.121 & -.085 & 1 & & \\
\hline $\mathrm{D}$ & -.144 & -.068 & $-.292 * *$ & 1 & \\
\hline $\mathrm{E}$ & $-.265^{* *}$ & -.144 & $-.211^{*}$ & $-.198^{*}$ & 1 \\
\hline
\end{tabular}

${ }^{\mathrm{y}}$ Item: $\mathrm{A}=$ pest control; $\mathrm{B}=$ weed management; $\mathrm{C}=$ crop management; $\mathrm{D}=$ public garden etiquettes; $\mathrm{E}=$ activities using harvest. ${ }^{*} p<.05,{ }^{* *} p<.01$.

Table 15. Relation between demographic characteristics and recognition about the most important item for garden management

\begin{tabular}{|c|c|c|c|c|c|c|c|c|}
\hline \multirow{2}{*}{ Characteristic } & \multirow{2}{*}{ Devision } & \multicolumn{5}{|c|}{ Frequency $(\%)^{z}$} & \multirow{2}{*}{$\chi^{2}$} & \multirow{2}{*}{$p$} \\
\hline & & Item A & Item B & Item $\mathrm{C}$ & Item D & Item $\mathrm{E}$ & & \\
\hline \multirow{2}{*}{ Gender } & Male & $8(7.2)$ & $10(9.0)$ & $26(23.4)$ & $16(14.4)$ & $4(3.6)$ & \multirow{2}{*}{1.685} & \multirow{2}{*}{$.793^{\mathrm{NS}}$} \\
\hline & Female & $8(7.2)$ & $5(4.5)$ & $17(15.3)$ & $15(13.5)$ & $2(1.8)$ & & \\
\hline \multirow{4}{*}{ Age } & $20 \mathrm{~s}$ & $3(2.7)$ & $7(6.3)$ & $10(9.0)$ & $8(7.2)$ & $2(1.8)$ & \multirow{4}{*}{14.802} & \multirow{4}{*}{$.252^{\mathrm{NS}}$} \\
\hline & $30 \mathrm{~s}$ & $6(5.4)$ & $0(0.0)$ & $17(15.3)$ & $7(6.3)$ & $2(1.8)$ & & \\
\hline & $40 \mathrm{~s}$ & $4(3.6)$ & $7(6.3)$ & $14(12.6)$ & $12(10.8)$ & $1(0.9)$ & & \\
\hline & $50 \mathrm{~s}$ & $3(2.7)$ & $1(0.9)$ & $2(1.8)$ & $4(3.6)$ & $1(0.9)$ & & \\
\hline \multirow{3}{*}{ Education Level } & High school & $0(0.0)$ & $0(0.0)$ & $0(0.0)$ & $1(0.9)$ & $0(0.0)$ & \multirow{3}{*}{5.149} & \multirow{3}{*}{$.742^{\mathrm{NS}}$} \\
\hline & University & $14(12.6)$ & $14(12.6)$ & $33(29.7)$ & $25(22.5)$ & $5(4.5)$ & & \\
\hline & Graduate school & $2(1.8)$ & $1(0.9)$ & $10(9.0)$ & $5(4.5)$ & $1(0.9)$ & & \\
\hline \multirow{11}{*}{ Region } & Seoul & $1(0.9)$ & $0(0.0)$ & $0(0.0)$ & $0(0.0)$ & $0(0.0)$ & \multirow{11}{*}{43.203} & \multirow{11}{*}{$.336^{\mathrm{NS}}$} \\
\hline & Metropolitan city & $1(0.9)$ & $0(0.0)$ & $2(1.8)$ & $4(3.6)$ & $0(0.0)$ & & \\
\hline & Gyeonggi-do & $3(2.7)$ & $2(1.8)$ & $5(4.5)$ & $5(4.5)$ & $2(1.8)$ & & \\
\hline & Gangwon-do & $3(2.7)$ & $2(1.8)$ & $4(3.6)$ & $2(1.8)$ & $1(0.9)$ & & \\
\hline & Chungcheongbuk-do & $2(1.8)$ & $0(0.0)$ & $4(3.6)$ & $5(4.5)$ & $0(0.0)$ & & \\
\hline & Chungcheongnam-do & $1(0.9)$ & $1(0.9)$ & $8(7.2)$ & $3(2.7)$ & $2(1.8)$ & & \\
\hline & Jeollabuk-do & $1(0.9)$ & $3(2.7)$ & $5(4.5)$ & $2(1.8)$ & $0(0.0)$ & & \\
\hline & Jeollanam-do & $0(0.0)$ & $4(3.6)$ & $3(2.7)$ & $3(2.7)$ & $0(0.0)$ & & \\
\hline & Gyeongsangbuk-do & $0(0.0)$ & $0(0.0)$ & $6(5.4)$ & $2(1.8)$ & $1(0.9)$ & & \\
\hline & Gyeongsangnam-do & $3(2.7)$ & $3(2.7)$ & $6(5.4)$ & $5(4.5)$ & $0(0.0)$ & & \\
\hline & Jeju island & $1(0.9)$ & $0(0.0)$ & $0(0.0)$ & $0(0.0)$ & $0(0.0)$ & & \\
\hline
\end{tabular}

${ }^{\mathrm{z}}$ Item: $\mathrm{A}=$ pest control; $\mathrm{B}=$ weed management; $\mathrm{C}=$ crop management; $\mathrm{D}=$ public garden etiquettes; $\mathrm{E}=$ activities using harvest.

${ }^{\mathrm{NS}}$ Non-significant by chi-square test.

\section{Perception gap on important items of garden management by demographic characteristics}

As a result of conducting $\chi^{2}$ test to compare the perception gap on items of garden management according to the demographic characteristics of urban garden participants, there was no statistically significant difference at the significance level of $5 \%$, indicating that there is no perception gap on the important items of garden management accord- ing to demographic characteristics (Table 15).

By gender, men showed the order of crop management $(23.4 \%)>$ public garden etiquettes among users $(14.4 \%)$ $>$ weed management $(9.0 \%)>$ pest control $(7.2 \%)>$ activities using harvest $(3.6 \%)$, and women showed the order of crop management $(15.3 \%)>$ public garden etiquettes among users $(13.5 \%)>$ pest control $(7.2 \%)>$ weed management $(4.5 \%)>$ activities using harvest $(1.8 \%)$, indicat- 
ing that crop management was most important for all respondents regardless of gender. By age, 50s selected 'public garden etiquettes among users' as most important, whereas $20 \mathrm{~s}, 30 \mathrm{~s}$, and $40 \mathrm{~s}$ selected 'crop management'. This may be due to the high age levels of public servants in charge of civil complaints among garden users that frequently occur in public gardens.

By education level, graduates of universities and graduate schools mostly selected crop management (29.7\%, 9.0\%, respectively), followed by public garden etiquettes among users $(22.5 \%, 4.5 \%$, respectively) $>$ pest control $(12.6 \%$, $1.8 \%$, respectively) and weed management $(12.6 \%, 0.9 \%$, respectively) $>$ activities using harvest $(4.5 \%, 0.9 \%$, respectively). For high school graduates, there was only one person who responded that 'public garden etiquettes among users' is important. This was consistent with the study by Kim (2018) that respondents with higher education level have more items demanded for garden management due to the different information accessibility depending on education level. By region, Seoul and Jeju selected 'pest control', Jeollanam-do selected 'weed management', metropolitan cities and Chungcheongbuk-do selected 'public garden etiquettes among users' as the important items, while Gyeonggi-do and Gyeongsangnam-do selected 'crop management'. This was consistent with the study by Lee (2013) that there is a difference in issues occurred by region due to the different support plans for urban agriculture in each local government, which implies that it is important to first determine the demand of urban residents along with administrative plans by region.

\section{Conclusion}

This study is a basic research to derive items that are most necessary in establishing garden management guidelines. It was conducted to determine the current state of public gardens operated by local governments as well as education and programs by conducting a survey on public servants at provincial institutes and city and county agricultural technology centers, and examine the items most required by urban residents for garden management.

For garden management status, there were 45 sites (40.5\%) with gardens operated by city and county local governments nationwide, $41(91.1 \%)$ of which have dedicated staff (1.8 persons on average), and the average area of gardens was $18,623 \mathrm{~m}^{2}$, garden area per person was $20.27 \mathrm{~m}^{2}$, the average number of participants was 683, and average period of use was 8.69 months. 14 (31.1\%) out of 45 sites were operating small group meetings for participants along with gardening activities, with average 2.29 meetings and 67 participants. In the satisfaction survey after gardening activities, $88.9 \%$ of 18 sites were satisfied.

In the survey on whether the site operated education and programs for garden users, all of them implemented education or programs in garden operation, with an average of 4 sessions per education and total expenses of KRW $34,077,740$, comprised of instructor fee KRW 10,313,950, material cost KRW 13,849,562 and other operating costs. With 683 participants in gardening and 4 sessions, it can be estimated that KRW 12,474 per person is spent in each session of education. The contents of education were in the following order basic education on garden cultivation $(33.9 \%)>$ prior education on garden operation $(28.9 \%)>$ pest control $(14.0 \%)>$ eco-friendly management $(11.6 \%)>$ pesticides and PL $(9.9 \%)>$ others $(1.7 \%)$, which included negligent accidents and on-site garden training. For the satisfaction survey after education and programs, 95.2\% responded that they were satisfied overall.

Regarding the perception survey on which items are necessary in establishing garden management guidelines, the most necessary items were in the order of crop management $(38.7 \%)>$ public garden etiquettes among users $(27.9 \%)>$ pest control $(14.4 \%)>$ weed management $(13.5 \%)>$ activities using harvest $(5.4 \%)$. The contents that are to be included preferentially in the guidelines were in the order of garden planning and crop selection $(17.2 \%)>$ cultivation techniques and schedules $(16.5 \%)>$ pest and soil management $(15.7 \%)>$ introduction of crops and gardening models $(12.7 \%)>$ garden etiquettes $(10.7 \%)$. The fact that public garden etiquettes among users was derived as a necessary item aside from the items on crops reflects the trend of times, showing that the contradiction between garden functions and publicness raises conflicts among garden users. Thus, it is necessary to enable users to use the common use space between gardens. 
For urban gardens, unlike general farms for production of agricultural products, urban residents use unused space and thus there are limitations in creating an environment suitable for plant growth. Recently, various types of products are cultivated in urban gardens, such as vegetables, plants, crops and flowers. Plants require separate management depending on the period and cause various pests, and thus users may face difficulty in managing and maintaining their gardens if they lack knowledge, experience and information about garden management. Therefore, it is necessary to provide customized information and management techniques for each region depending on the environmental and geographical characteristics, and develop and supply operating manuals or management guidelines to easily use such information. Moreover, there must be support on soil analysis, methods, farming machinery as well as technical support on garden management led by local governments to facilitate garden management.

This study has limitations in that the questionnaire was not retrieved within the deadline due to absence of public servants in charge, thereby failing to provide data on all public gardens. An increase in samples may produce different results. Nonetheless, the results have reflected the needs of actual users in making urban garden operation plans by region, and thus may have high utility value as the basic data for continuous garden management. In the future, the findings of this study can be used to come up with detailed factors that can guarantee sustainability of urban gardens, promote satisfaction of users and operation of urban agriculture, and provide high-quality data for research and development of education programs on urban agriculture. The results are expected to be used in establishing desirable measures for garden management and maintenance to continuously activate and promote urban agriculture.

\section{References}

Cho, M.J. 2015. A study on the formation process of public urban farm. Master's thesis, Dong-A University, Busan, Korea.

Choi, E.Y. 2016. Urban farming activation plan through the analysing of urban farming ordinance. Master's the- sis, Korea University, Seoul, Korea.

Hong, I.K., Y. Chae, Y.N. Jang, S.M. Lee, and J.N. Su. 2018. Analysis of urban agricultural effects by factors according to the urban citizens income level:socially sustainable effect, negative effect, and economically sustainable effect. J. People Plants Environ. 21(6):461-471. http://doi.org/10.11628/ksppe.2018.21.6.461

Hong, I.K., Y. Chae, S.M. Lee, and Y.B. Jung. 2019. An exploration of crops listed in Gwanhyji, an agricultural book in the joseon dynasty for the promotion of the diversity of urban gardens. J. People Plants Environ. 22(4):341-354. http://doi.org/10.11628/ksppe.2019.22.4.341

Jang, B.G., Y.J. Choi, and C.C. Cho. 2012. A study on assessment of urban agriculture education program: Focused on urban agriculture instructor course at Gyeonggi Provincial Agricultural Research \& Extension Services. J. Agric. Ext. Community Dev. 19(2):273-299.

Kang, J.H. 2016. Using statistical analysis according to the new spss program. Seoul, Korea: Crownbook Press.

Kim, H.R. 2018. A study on the perception of and satisfaction with urban farming management. Doctoral dissertation, Chonbuk National University, Jeonju, Korea.

Kim, M.S., Y.N. Jeong, and S.Y. KIM. 2015. Current status and implications on managing vegetable garden in apartment complexes. J. Archit. Inst. Korea Plan. Des. 31(3): 143-154. https://doi.org/10.5659/JAIK_PD.2015.31.3.143

Lee, D.G. 2013. A study of the preference on the type of urban agriculture and activity preferences by lifestyle. Master's thesis, Hanyang University, Seoul, Korea.

Lee, W.S. 2017. A study on evaluating the diverse value of urbqan agriculture and its activation plan. Doctoral dissertation, Seoul National University, Seoul, Korea.

Ministry of Agriculture, Food and Rural Affairs. 2011. Urban agriculture development execution plan. Sejong, Korea: Author.

Ministry of Agriculture, Food and Rural Affairs. 2017. Introduced the national professional qualification: Urban agricultural management (pp. 1-3). Sejong, Korea: Author.

Nam, K.H. 2013. A study on the publicity of the urban park according to creating community gardens. Master's thesis, University of Seoul, Seoul, Korea.

Park, T.H. 2012. Effects of urban farming program on the participants' sense of community. Master's thesis, University 
of Seoul, Seoul, Korea.

Youn, E.S. 2018. A comparative study on the operation status and user's perceptions of urban garden fields. Master's thesis, Daegu Hanny University, Daegu, Korea. 